\title{
Crosstalk between Autophagy and Apoptosis Modulates T-2 Toxin-Induced Toxicity in
}

\section{Liver Cells}

Jing Wu ${ }^{\mathrm{a}, \mathrm{c}, \mathrm{d}}$, Yu Zhou ${ }^{\mathrm{a}}$, Zhihang Yuan ${ }^{\mathrm{a}, \mathrm{c}, \mathrm{d}}$, Jine $\mathrm{Yi}^{\mathrm{a}}$, Jingshu Chen ${ }^{\mathrm{b}}$, Naidong Wang ${ }^{\mathrm{a} *}$ and Yanan $\operatorname{Tian}^{\mathrm{a}, \mathrm{b} *}$

${ }^{\mathrm{a} C o l l e g e}$ of Veterinary Medicine, Hunan Agricultural University, Changsha, Hunan 410128, P.R.China

${ }^{b}$ Department of Veterinary Physiology and Pharmacology, College of Veterinary Medicine, Texas A\&M University, College Station, TX 77843, USA

${ }^{\mathrm{c}}$ Hunan Collaborative Innovation for Utilization of Botanical Function Ingredients, Hunan Agricultural University, Changsha, Hunan 410128, P.R.China

${ }^{\mathrm{d} H u n a n}$ Engineering Research Center of Veterinary Drug, Hunan Agricultural University, Changsha, Hunan 410128, P.R.China

*Corresponding author:

Naidong Wang, Ph.D., Associate Professor.,

College of Veterinary Medicine, Hunan Agricultural University (HAU), 1\# Nongdalu Rd, Furong district, Changsha, Hunan, 100071, PR China

Phone: 86-731-84673712

Fax: 86-731-84673618

Email:naidongwang@hunau.edu.cn

Yanan Tian, Ph.D., Associate Professor

College of Veterinary Medicine, Texas A\&M University,

College Station, TX 77843, USA

Phone: 979-458-3599

Fax: 979-862-4929

Email:ytian@crm.tamu.edu 


\section{Acknowledgements}

This project was supported by the National Natural Science Foundation of China (Grant No. 31302157), China Postdoctoral Science Foundation ((Grant No. 2017M620346), Scientific Research Project of Hunan Provincial Education Department (Grant No. 17B125) 


\begin{abstract}
T-2 toxin produced by fungi of Fusarium genus is highly toxic to human and animals and has been shown to induce apoptosis in various organs/tissues. Apoptosis and autophagy are interconnected processes and these interactions are important for cellular homeostasis as well as pathogenesis. In this study, we report for the first time that T-2 toxin induced autophagy in human liver cells (L02). We showed that T-2 toxin induced the formation of acidic vesicular organelles, concordant with the time and dose-dependent alterations in LC3-phosphatidylethanolamine conjugate (LC3-II) LC3-I/II and p62/SQSTM1 suggesting an enhanced autophagic flux. The T-2 toxin-induced formation of autophagosome and lysosomal fusion was observed by expressing mRFP-GFP-LC3 in L02 cells by lentiviral transduction, and autophagosome was observed by transmission electron microcopy. We found that while T-2 toxin activated both apoptosis and autophagy, activation of autophagy appears to be a leading event reflecting the protective mechanism of cells against the insults by T-2 toxin. Activating autophagy by rapamycin (RAPA) inhibited the apoptosis while suppressing autophagy by chloroquine greatly enhanced the T-2 toxin-induced apoptosis suggesting the crosstalk of autophagy and apoptosis. In summary, our study showed that activation of autophagy protects liver cells from $\mathrm{T}-2$ toxin-induced apoptosis suggesting autophagy may be targeted for prevention of the T-2 toxin-induced toxicity in human and animals.
\end{abstract}

Keyword: T-2 toxin, toxicity, autophagy, apoptosis 


\section{Introduction}

T-2 toxin is a metabolite synthesized by fungi of Fusarium genus including F. poae, F. sporotrichioides, F. armeniacum, and F. langsethiae. The Fusarium fungi are prevalent T-2 toxin-producing fungi in the northern temperate regions and have been commonly found in food and feedstuff of cereal origin including wheat, barley, rice crops and oats grown in regions throughout America, Europe, and Asia. Therefore, T-2 toxin contamination is an ubiquitous problem $[1,2]$.

T-2 toxin is a trichothecene (3-hydroxy-4-15-diacetoxy-8ct-(3-methyl butyryloxy) 12,13 epoxytrichothec-9-ene) substituted by an epoxy trichothecene ring structure. It belongs to a group of type A trichothecenes [3,4]. T-2 toxin is the most cytotoxic member of the trichothecene family and it has been found to induce various toxic responses in a wide range of the cell types including human chondrocytes, HL-60, Hela, Bel-7402 and Chang liver cells, involving cellular factors that are important for cell cycle, apoptosis and stress responses such as Fas, p53, Bcl-xL, Bcl-2, Bax, caspase-9/caspase-3 and JAK/STAT (Janus kinase/signal transducers and activators of transcription) signaling pathways [5-7] [8]. T-2 toxin has been shown to have radiomimetic effects and cause inhibition of the syntheses of protein, DNA and RNA in eukaryotic cells $[9,10] . \quad$ It has been shown that $\mathrm{T}-2$ toxin affected the cell cycle, and induced apoptosis in chondrocytes [11,12], human astrocytes [13], and murine embryonic stem cells [14], porcine primary hepatocytes [15]. T-2 toxin has been shown to be highly toxic to cells with high proliferating activity such as hematopoietic cells in the bone marrow and splenic red pulp [16], and epidermal basal cells [17]. We and others have shown T-2 toxin elicited endocrine disruptive effects at low dose in mouse granulosa cells [18] and toxic to the reproductive organ $[9,10,19]$.

At cellular and molecular levels, exposure to T-2 toxin causes apoptosis which is often initiated by oxidative stress responses and subsequently causes cells to enter the mitochondrial death pathway $[14,20,21]$. The oxidative stress is marked by down-regulated activity of glutathione peroxidase (GSH-Px) and catalase (CAT) with induction of the reactive oxygen species (ROS) leading to damage of cellular components as indicated by the increased in DNA damage and heightened lipid peroxidation marked by the increases in intracellular malondialdehyde (MDA). We have shown that antioxidant in grape seed extract could protect 
cells from T-2 toxin induced apoptosis by reducing the oxidative stresses in cells [22].

Apoptosis is a highly regulated process that an organism utilized for a process of programmed cell death, and autophagy on the other hand is an evolutionarily conserved cellular process for degradation and recycling of defective organelles and proteins to maintain cellular homeostasis [23]. Autophagy enables cells to cope with various stresses, such as nutrient deprivation, endoplasmic reticulum (ER) stress, pathogen infection, or hypoxia and is considered as a survival mechanism [24]. Indeed, these two processes share many factors commonly used in the response to the diverse stimuli, though often with different kinetics in which autophagy is initiated prior to the induction of apoptosis. Once cells that are unable to cope with the stressor through autophagy, apoptosis may ensue. Consistent with this notion, a variety of autophagic proteins, including ATG3, Beclin-1, and AMBRA1, have been shown to be targeted for caspase-mediated destruction during apoptosis [25-28] and autophagic and apoptotic pathways may become intertwined to affect cell fate [29].

We previously reported that T-2 toxin induces apoptosis through ROS-mediated mitochondrial pathways in ovarian granulosa and TM3 Leydig cells [21,30]. But as far as we know, there are no information concerning effects of T-2 toxin on autophagy in cells. Therefore, the present study is to investigate the role of autophagy in T-2 toxin-induced toxic responses and to analyze the potential crosstalk between these two processes in normal human liver cell line L02.

\section{Results}

\subsection{T-2 toxin induced cytotoxicity effect and oxidative stress in L02 cells}

L02 is a human fetal liver cell line which has been shown to exhibit features of liver function in vitro and has been used as a cell culture model to characterize the liver damage. In L02 cells, treatment with increasing amounts of T-2 toxin $(0,0.2,1,5,25$ and $125 \mathrm{nM}, 12 \mathrm{~h})$ induced a typical concentration-dependent inhibition of cellular proliferation and at low dose $(0.2 \mathrm{nM})$, T-2 toxin started to cause a significant decrease of cellular viability while the vehicle control ( $1 \%$ ethanol) had no effect on L02 cell viability. Based on these dosage effects, 0, 0.2, 1 and $5 \mathrm{nM} \mathrm{T}-2$ toxin were selected as the dose range for subsequent experiments (Fig.1A). $12 \mathrm{~h}$ 
after T-2 toxin treatment, L02 cells exhibited significantly higher levels of ALT, AST and LDH in the culture medium which are indicative of liver cell damage (Fig.1 B and C). As shown in Fig.1 D, T-2 toxin treatments $(0.2-5 \mathrm{nM}, 12 \mathrm{~h})$ significantly decreased GSH-PX, CAT activities, and MDA content were increased in L02 cells treated with T-2 toxin $(0.2-5 \mathrm{nM})$ indicating oxidative stress-induced damage.

\subsection{T-2 toxin induced apoptosis in $\mathrm{LO2}$ cells}

Cellular apoptosis often leads to cleavage of Poly [ADP-ribose] polymerase 1 (PARP-1). As the substrate of caspase-3, activated PARP-1 can be cleaved into 21 and $89 \mathrm{kDa}$ fragments which is used as an indication for apoptosis. Cleavage of PARP-1 was significantly elevated in L02 cells induced by T-2 toxin in a concentration-dependent manner, concordant with the expression of cleaved-caspase-3 (Fig.2A). As prototypes of the regulatory proteins of apoptosis, we examined the levels of the Bax and Bcl-2 proteins in L02 cells, and the results indicated a significant increase of Bax/Bcl-2 ratio (Fig.2A). In a time course study, L02 cells were exposed to $5 \mathrm{nM}$ T-2 toxin for different time points (0-12h), and cleavage of PARP-1 and caspase- 3 were elevated and peaked at $6 \mathrm{~h}$, then decreased afterwards. The Bax/Bcl-2 ratio was increased in a time-dependent manner (Fig.2B).

To further test whether T-2 toxin causes the apoptosis of L02 cells, flow cytometry was used to identify and quantitate apoptotic cells. Staining cells simultaneously with FITC-Annexin V (green fluorescence) and the non-vital dye propidium iodide (red fluorescence) allows the discrimination of intact cells $\left(\mathrm{FITC}^{-} \mathrm{PI}^{-}\right)$, early apoptotic $\left(\mathrm{FITC}^{+} \mathrm{PI}^{-}\right)$and late apoptotic or necrotic cells $\left(\mathrm{FITC}^{+} \mathrm{PI}^{+}\right)$. In the flow cytometry, there are two-parameter dot plots: left bottom quadrant shows viable cells; right bottom quadrant for early apoptotic cells; right upper quadrant for late apoptotic cells, while the left upper quadrant for non-living cells, namely the necrotic cells. As shown in Fig. 2C, after treatment with T-2 toxin for $12 \mathrm{~h}$, numbers of apoptotic cells were increased in a dose-dependent manner. Moreover, cells were stained with Hoechst 33258 for nuclei observation, the number of apoptotic cells with shrunken and irregularly shape or degradation with aggregation and fragmentation of chromatin significantly increased with T2 toxin treatment. Untreated cells had regular contours and were round and large in size (Fig. 2D). 


\subsection{T-2 toxin induced autophagy in L02 cells}

We analyzed conversion of LC3-I to LC3-II, a biochemical marker of autophagy, by western blotting. Treatment with T-2 toxin led to a significant decrease of LC3-II level (Figure 3A). To investigate molecular mediators in T-2 toxin-induced autophagy, we analyzed the change of p62 (a poly-ubiquitin binding protein that binds to LC3 and is degraded by autophagy) and beclin-1 (a component of the autophagy-specific PtdIns3K complex). The results showed the level of p62 and beclin-1 decreased significantly in L02 cells compared with control cells (Fig. 3B). Interestingly, p62 and beclin-1 decreased significantly after an increase and tends to peak at $3 \mathrm{~h}$ in L02 cells treated with 5nM T-2 toxin, and the conversion of LC3-I to LC3-II decreased in a time-dependent manner (Fig.3B).

Next, to investigate whether T-2 toxin treatment induces autophagy, we assessed the formation of acidic vesicular organelles (AVOs) and autolysosomes, both hallmarks of autophagy. Acridine orange is a cell-permeable green fluorophore that can be protonated and trapped in AVOs. It is bright green in the cytoplasm and nucleus but emits dim red fluorescence in acidic vesicles such as autolysosomes. This makes acridine orange staining a quick, accessible and reliable method to assess autophagy induction. T-2 toxin enhanced the formation of acidic vesicular organelles (red foci in the cells) in L02 cells compared to control cells (no apparent red staining) (Fig.3C).

We used TEM to analyze acidic vesicular organelles and autolysosomes, respectively. At higher magnifications autophagosomes were clearly distinguished from intense electron-dense lysosomal structures (red arrow, Fig.3D), and apoptosis was also observed due to nuclear pyknosis (yellow arrow, Fig.3D) following T-2 toxin treatments.

Finally, we utilized the tandem RFP-GFP-LC3 lentivirus construct to further confirm autophagy induction as indicated by formation of punctate, which represents autophagosome formation as described and autophagic flux. The rationale of this assay is based on the $\mathrm{pH}$ difference between the acidic autolysosome and the neutral autophagosome and the $\mathrm{pH}$ sensitivity differences exhibited by green fluorescent protein (GFP) and red fluorescent protein (RFP) to monitor progression from autophagosome to autolysosome. When an autophagosome fuses with a lysosome to form autolysosomes, the GFP moiety degrades from the tandem protein, but RFP-LC3 maintains the puncta. As shown in Fig.3E, after transduction with the 
RFP-GFP-LC3 lentiviral construct into the cells, we observed the successful introduction of the viruses showing both fluorescent proteins. In addition to reduction of LC3, which was consistent with previous protein results (Fig.3A), there were more red puncta associated with T-2 toxin treatment (Fig. 3E). These results provide further confirmation of the induction of autolysosome formation, indicating that T-2 toxin mediated autophagy flux in L02 cells.

\subsection{Autophagy blocks T-2 toxin-induced apoptosis}

To investigate the effect of autophagy on T-2 toxin-induced apoptosis, an activator and inhibitor of autophagy, RAPA and CQ were utilized. Results from immunoblotting indicate that T-2 toxin inhibited expression of LC3-II, p62 and beclin-1, cleaved PARP-1 and caspase3, and increased Bax/Bcl-2 ratio (Fig.4A-D), while co-treatment with RAPA increased expression of LC3-II and Beclin-1, and decreased expression of p62, cleavage of PARP-1 and caspase-3, and did not have a significant impact on Bax/Bcl-2 ratio (Fig.4A, B), co-treatment with CQ increased expression of LC3-II and cleavage of caspase-3, decreased expression of Beclin-1 (Fig.4C, D). Flow cytometry analysis demonstrated that treatment of L02 cells with $5 \mathrm{nmol} / \mathrm{L} \mathrm{T}-2$ toxin and $100 \mu \mathrm{mol} / \mathrm{L}$ CQ induced a higher apoptosis rate compared with T-2 toxin treatment alone (Fig. 4E).

\section{Discussion}

In recent years, it has been increasingly recognized that apoptosis and autophagy are interconnected cellular processes sharing regulatory components. As a major pathological cellular process, apoptosis induced by T-2 toxin has been characterized in different tissues and organs, however, the role of the autophagy in the T-2 toxin-induced toxic responses has not been well understood.

Hepatocytes possess major detoxification enzymatic systems with active autophagy processes. Using liver cell line L02 as the in vitro model, we demonstrated that the effect of autophagy on T-2 toxin-induced apoptosis. We began by evaluating the toxic effect of T-2 toxin on the cells. The rise in ALT activity of blood is almost always due to hepatocellular damage and is usually accompanied by a rise in AST, and LDH which is an enzyme found inside every living cell [31]. When hepatocellular membrane integrity is compromised, the presence of these enzymes in the culture medium can be used as an indicator for cell death. The 
cytotoxicity of T-2 toxin in the liver cells was evaluated in L02 cell culture model and T-2 toxin is highly toxic to the liver cells with significant toxicity appeared at $0.2 \mathrm{nM}$ as indicated by rises of ALT, AST and LDH in the culture media in a T-2 toxin concentration-dependent manner (Fig.1A, B, C). Similar results were also reported in other relevant studies [32,33].

One major mechanism for cytotoxicity of T-2 toxin is the induction of oxidative stress by T2 toxin $[20,30,34,35]$. Oxidative stress is tightly controlled by the endogenous antioxidant enzymatic system, which regulates cellular antioxidant capacity. Our results showed that T-2 toxin caused decreases in GSH-Px and CAT activity with concomitant increases in MDA concentrations indicating increased lipid peroxidation [36] which is known to cause damage to the critical cellular components [37]. The decreases in the levels of GSH-Px and CAT (Fig.1D) are consistent with the reduced antioxidant capacity induced by T-2 toxin.

It has been reported T-2 toxin could induce apoptosis through oxidative stress $[14,20,21,30]$. PARP-1, Bax, Bcl-2 and caspase-3 are critical regulatory proteins of the apoptotic pathway. The nuclear enzyme poly (ADP-ribose) polymerase-1 (PARP-1) hyperactivity in the nucleus rapidly impairs ATP production in mitochondria, whereas release of the pro-apoptotic factors AIF/Cyt$c$ from mitochondria only occurs several hours after PARP-1 hyperactivation leading to PARP1-dependent cell apoptosis [38]. Members of the Bcl-2 family regulate the intrinsic mitochondrial mediated apoptotic pathway [39]. The Bcl-2 family includes pro-apoptotic and anti-apoptotic members, and the balance between these counteracting proteins presumably determines cell fate [40]. Pro-apoptotic Bcl-2-like proteins, including Bax, promote apoptosis by opening the mitochondrial voltage-dependent anion channel to cause permeabilization of the mitochondrial outer membrane and the release of other pro-apoptotic factors [41], which is opposite to Bcl-2. In our experimental model, L02 cells treated with T-2 toxin showed an increase in cleavage of PARP-1 and Bax/Bcl-2 ratio (Fig.2A). This leads to activation of caspase-9 and triggers a downstream caspase cascade [42]. Caspases are a family of cysteine proteases which are activated during the apoptotic processes. They are activated from precursors to functional forms by partial cleavage events, and caspase- 3 is a prevalent caspase that is ultimately responsible for the majority of apoptotic processes [43]. After treatment with T-2 toxin, the activities of caspases-3 of L02 cells was increased, and apoptotic cells were concentrations-dependent increase (Fig.2A, C). 
Apoptosis is also associated with a series of morphological changes characterized by the cell shrinkage, chromatin condensation and the formation of apoptotic bodies [44]. The apoptotic morphological changes could also be observed in T-2 toxin-treated L02 cells, revealed cell shrinkage and chromatin condensation (Fig.2D).

It has been previously suggested that autophagy and apoptosis can occur simultaneously, and autophagy can be induced by some inducers of apoptosis [45]. During induction of autophagy, the nonlipidated form of LC3 (LC3-I, $18 \mathrm{kDa}$ ) converted into the lipidated form LC3 (LC3-II, $16 \mathrm{kDa}$ ), which is associated with autophagosome biogenesis, and activity of autophagy is associated with changes of the cellular level of LC3-II [46]. The autophagy is a dynamic process and steady state levels of LC3-II amount at a given time point does not necessarily provide real time estimate of the autophagic activity, because not only autophagy activation but also inhibition of autophagosome degradation greatly increases the amount of LC3-II. Also, part of LC3-II is destroyed together with cargo in autophagolysosomes, so its levels may be both increased or decreased in the conditions of upregulated autophagy [47-51]. Degradation of p62 is another widely used marker to monitor autophagic activity because p62 directly binds to LC3 and is selectively degraded by autophagy [48,52,53]. Our results showed increases in autophagosomes and decreases in expression levels of LC3-II and p62 after T-2 toxin treatment in L02 cells (Fig.3A, C, D). It has been shown that LC3-II/LC3-I ratio would decrease if the degradation process of LC3-II by lysosomal is rapid. Furthermore, LC3 changes may be particularly rapid, while clearance of substrates of autophagy may need a longer time [54]. Thus, lower LC3-II/LC3-I and p62 suggested enhancing autophagy activity and ongoing autophagic flux induced by T-2 toxin, consistent with the results using the GFP-RFP-tandem fluorescent LC3 (tf-LC3) method which monitors autolysosome formation (Fig 3E). Moreover, to measure the autophagic flux, it is essential to determine how much LC3-II (as a model substrate of autophagy) is degraded in a lysosome-dependent manner during a certain time period. Thus, we used chloroquine to inhibit autophagy pathway. It was well known that chloroquine inhibited lysosome fusion with autophagosomes and elevated lysosomal $\mathrm{pH}$, thereby preventing the final digestion step and inhibiting lysosomal activity. As expected, compared with T-2 toxin treatment alone the ratio of LC3-II/LC3-I increased in co-treatment with CQ for 6h (Fig.4C). 
Beclin 1 is at the central stage of phagophore formation or autophagy initiation [55](Fu et al., 2013). In normal status, Beclin 1 interacts with Bcl-2 therefore its activity is restricted by Bcl2. Activated autophagy with increased Beclin 1 expression was observed when Bcl-2 was silenced by siRNA in cultured pterygium epithelial cells [55-57]. In several settings, including TRAIL, chemotherapy, irradiation, immunotherapy, nutrient deprivation, angiogenesis inhibitors and hypoxia, Beclin 1 has an anti-apoptotic role. In C. elegans, depletion of Beclin 1 triggers CED-3/caspase-dependent programmed cell death [58]. Interestingly, caspases can cleave Beclin 1 in apoptosis, thereby destroying its pro-autophagic activity. For example, caspase-3-, 7- and 8-mediated cleavage of Beclin 1 generates $\mathrm{N}$ - and C-terminal fragments that lose their ability to induce autophagy. The C-terminal fragments translocate to mitochondria and sensitize cells to apoptotic signals. This process represents an amplifying loop for inducing massive apoptotic cell death. Apoptosis induced by the proapoptotic protein Bax reduced autophagy by enhancing caspase-mediated cleavage of Beclin 1 at D149. Caspase-mediated cleavage of Beclin 1 promotes crosstalk between apoptosis and autophagy $[26,59,60]$. Our study showed that treatment with T-2 toxin caused decreases in Beclin-1 and Bcl-2 with cleavage of caspase-3, suggesting that autophagy and apoptosis share common stimuli and signaling pathways, and apoptosis is ultimately a dominant process.

Although the present study demonstrated that $\mathrm{T}-2$ toxin induced apoptosis and autophagy in L02 cells, the correlation between apoptosis and autophagy induced by T-2 toxin is unknown. In order to elucidate the correlation, L02 cells were exposed to $5 \mathrm{nM} \mathrm{T-2}$ toxin for different time (0-12h). Detection of apoptotic-associated proteins revealed cleavage of PARP-1 and caspase3 were elevated and peaked at $6 \mathrm{~h}$, then gradually decreased, and the $\mathrm{Bax} / \mathrm{Bcl}-2$ ratio was increased in a time-dependent manner (Fig.2B). While detection of autophagy-associated proteins showed p62 and Beclin-1 decreased significantly after an increase and tends to the peak at 3h, and the conversion of LC3-I to LC3-II decreased in a time-dependent manner (Fig.3B). The present results suggested it was caused by autophagy that apoptosis reached a peak at a specific time and began to decline gradually, and autophagy was inhibitory against the apoptosis induced by T-2 toxin in L02 cell. To further confirm this conclusion, T-2 toxin was used in combination with the autophagy stimulator RAPA and the autophagy inhibitor CQ to detect the expression levels of autophagy-associated and apoptosis-associated proteins and 
apoptosis rate induced by T-2 toxin in the L02 cells. As expected, the results showed that the autophagy stimulator RAPA increased expression of LC3-II and Beclin-1, and decreased expression of p62, cleavage of PARP-1 and caspase-3, and did not have a significant impact on Bax/Bcl-2 ratio (Fig.4A, B), suggests that enhanced autophagy could inhibit the apoptosis induced by T-2 toxin in L02 cells. Autophagy inhibitor CQ increased expression of LC3-II and cleavage of caspase-3, decreased expression of Beclin-1 (Fig.4C, D). Flow cytometry analysis demonstrated that treatment of L02 cells with $5 \mathrm{nmol} / \mathrm{L} \mathrm{T}-2$ toxin and $100 \mu \mathrm{mol} / \mathrm{L}$ CQ induced a higher apoptosis rate compared with T-2 toxin treatment alone (Fig. 4E). These results demonstrated that inhibition of autophagy through blocking autophagy flux could promote T-2 toxin-induced apoptosis in T-2 toxin.

Taken together, the results from present study suggest that T-2 toxin-induced toxic responses in the liver cells involve intricate interactions between the autophagy and apoptosis (Fig 5). While T-2 toxin treatment can activate both processes, activation of autophagy appears to be an initial event in T-2 toxin-treated L02 cells reflecting the protective mechanism of cells against the injurious insults. At overwhelming dose of T-2 toxin $(5 \mathrm{nM}, 12 \mathrm{~h})$, the apoptosis became a dominant process. The results of this study also suggest that the toxicity induced by T-2 toxin can be alleviated through selectively activating autophagy by pharmacological/chemopreventive agents such as RAPA, which counteracts the T-2 toxininduced apoptosis.

\section{Materials and methods}

\subsection{Chemicals}

T-2 toxin was purchased from Cayman Chemical (Ann Arbor, USA). 3-[4,5-dimethylthiazol2-yl]-2,5-diphenyltetrazolium bromide (MTT), Acridine orange(AO), Bicinchoninic acid (BCA) protein assay kit, Hoechst 33258 staining kit, Annexin V-FITC apoptosis detection kit and LDH cytotoxicity assay kit were purchased from Beyotime (Nantong, China). Aspartate transaminase (AST) assay kit, alanine transaminasetotal (ALT) assay kit, superoxide dismutase (SOD) assay kit, catalase (CAT) assay kit, cellular glutathione peroxidase (GSH-PX) assay kit 
and lipid peroxidation (MDA) assay kit were obtained from Nanjing KeyGen Biotech. Co. Ltd (Nanjing, China). Rabbit monoclonal anti-Bcl-2 antibody, rabbit monoclonal anti-Bax antibody, rabbit monoclonal anti-PARP-1 antibody, rabbit monoclonal anti-Caspase-3 antibody, rabbit monoclonal anti-P62 antibody, rabbit monoclonal anti-Beclin-1 antibody, rabbit monoclonal anti-LC3 antibody, mouse monoclonal anti- $\beta$-actin antibody, goat anti-rabbit IgG-HRP an goat anti-mouse IgG-HRP were obtained from Proteintech (Rosemont, USA). rapamycin (RAPA) and chloroquine diphosphate salt (CQ) were obtained from solarbio (Beijing, China). pGMLVCMV-RFP-GFP-hLC3 lentivirus was purchased from Genomeditech (Shanghai, China).

\subsection{Cells culture}

The human non-tumor cell line, L02, was obtained from China Cell Culture Center (Shanghai). The cell was maintained in an atmosphere of $5 \% \mathrm{CO}_{2}$ at $37^{\circ} \mathrm{C}$ in RPMI-1640 medium (Hyclone, USA) supplemented with 10\% fetal bovine serum (FBS; Hyclone). The L02 cells were cultured for $24 \mathrm{~h}$ ( $35 \mathrm{~mm}$ culture dishes, $25 \mathrm{~cm}^{2}$ culture flasks or 96 well culture plates) at a concentration of $0.5-1 \times 10^{6}$ cells $/ \mathrm{ml}$ before giving the different treatments.

The T-2 toxin was dissolved in 100\% ethyl alcohol and further diluted with 1640 based on the treatment concentrations. The serum-RPMI-1640 medium was removed and replaced with fresh serum-RPMI-1640 medium containing different concentrations T-2 toxin $(0-125 \mathrm{nM})$ for $12 \mathrm{~h}$, and the appropriate concentration of T-2 toxin was determined for subsequent experiments. The final ethanol concentration of each treatment used is $1 \%(\mathrm{v} / \mathrm{v})$. To investigate the relationship between apoptosis and autophagy in T-2 toxin-induced cell damage, cultures were pre-treated with autophagy inhibitor CQ $(100 \mu \mathrm{M})$ for $1 \mathrm{~h}$, and exposure to the inhibitor was continued during subsequent T-2 toxin $(5 \mathrm{nM})$ treatment for $6 \mathrm{~h}$. In other experiments, cultures were pre-treated with autophagy stimulator RAPA $(100 \mathrm{nM})$ for $24 \mathrm{~h}$, and exposure to the stimulator was continued during subsequent T-2 toxin $(5 \mathrm{nM})$ treatment for $12 \mathrm{~h}$.

\subsection{Determination of cell viability}

The cell viability was measured by MTT assay after $12 \mathrm{~h}$ treatment in 96-well culture plates. Briefly, the treatment media were replaced with MTT $(0.25 \mathrm{mg} / \mathrm{ml})$ and incubated at $37^{\circ} \mathrm{C}$ for $4 \mathrm{~h}$. The MTT was carefully removed and replaced with $150 \mu \mathrm{l}$ dimethyl sulfoxide (DMSO) to 
dissolve the formazan blue crystals. The absorbance (optical density) of each well was measured at $492 \mathrm{~nm}$ using a microplate reader (Infinite ${ }^{\circledR}$ M1000 Pro, TECAN, Austria). The data were normalized and computed using the optical density of the control treatment which was considered $100 \%$ viable.

\subsection{Evaluation of T-2 toxin-induced cytotoxicity}

For evaluation of T-2 toxin-induced cytotoxicity, we examined LDH, AST and ALT release from hepatocytes into culture media according to the manufacturer's recommended protocol. The results were normalized by the protein concentrations of cells lysates.

\subsection{Measurement of oxidative stress parameters}

The L02 cells were collected for detecting the activities of SOD, CAT, and GSH-Px, and contents of MDA by biochemical methods following the instructions of the corresponding reagent experiment kits. The results were normalized by the protein concentrations of cells lysates.

\subsection{Determination of apoptotic cells}

After treatment, L02 cells were collected and washed with PBS, and suspended in PBS at a concentration of $1 \times 10^{6}$ cells $/ \mathrm{ml}$, and $100 \mu \mathrm{l}$ cell suspension was transferred into a $5 \mathrm{ml}$ tubes, and stained with FITC-Annexin V (green fluorescence) and the non-vital dye propidium iodide (red fluorescence) allows the discrimination of intact cells (FITC-PI-), early apoptotic $(\mathrm{FITC}+\mathrm{PI}-)$ and late apoptotic or necrotic cells $(\mathrm{FITC}+\mathrm{PI}+)$. The mixture was gently vibrated and incubated for $15 \mathrm{~min}$ in the dark place, and then $400 \mu \mathrm{L}$ of $1 \times$ binding buffer was added to each tube. The hepatic apoptosis was analyzed by BD FACS Calibur flow cytometer within 45 min. There are two parameter dot plots in flow cytometry: bottom left quadrant shows viable cells; bottom right quadrant shows early apoptotic cells; upper right quadrant shows late apoptotic cells and, lastly, the upper left quadrant shows necrotic cells. The apoptotic cell morphology was determined using Hoechst 33258 stain. Hoechst 33258 is a blue fluorescent dye that can easily permeate cell membrane that allows determination of cells with fragmented 
and condensed chromatin. After treatment, L02 were washed twice with cold PBS and fixed using $4 \%$ formaldehyde for $10 \mathrm{~min}$. The fixed cells were washed three times, stained and incubated with Hoechst $33258(5 \mathrm{mg} / \mathrm{l})$ for $10 \mathrm{~min}$ at $37^{\circ} \mathrm{C}$ in a humidified chamber protected from light. Cells were washed three times with cold PBS and mounted with one drop of mounting solution. Cell nuclei were observed and imaged under an inverted fluorescence microscope (DMI 3000 B, Leica Microsystems Ltd.) with excitation at $350 \mathrm{~nm}$ and emission at $460 \mathrm{~nm}$.

\subsection{Determination of autophagy}

The L02 cells were grown on glass coverslips, treated for $12 \mathrm{~h}$ with different concentrations T-2 toxin following fixation with a solution containing 3\% glutaraldehyde plus $2 \%$ paraformaldehyde in $0.1 \mathrm{~mol} / \mathrm{L}$ cacodylate buffer $(\mathrm{pH}$ 7.3) for $1 \mathrm{~h}$. After fixation, the samples were post fixed at $1 \% \mathrm{OsO} 4$ in the same buffer for $1 \mathrm{~h}$ and then subjected to the electron microscopic analysis. Representative areas were chosen for ultrathin sectioning and viewed with a Transmission electron microscope (TEM) at an accelerating voltage of $80 \mathrm{kV}$. Digital images were obtained by the AMT imaging system.

After treatment of T-2 toxin, L02 cells were washed with PBS and incubated in PBS containing $2 \mu \mathrm{g} / \mathrm{ml}$ acridine orange for $30 \mathrm{~min}$ at $37^{\circ} \mathrm{C}$ in a humidified chamber protected from light. Then, cells were washed five times with PBS and observed under an inverted fluorescence microscope (DMI 3000 B, Leica Microsystems Ltd.) with excitation at $515 \mathrm{~nm}$ and emission at $488 \mathrm{~nm}$.

\subsection{Determination of autophagy flux}

The L02 cells were seeded on the culture plate, and moderate RFP-GFP-LC3 lentivirus were added to the plate according to the instructions, the cells were propagated in RPMI 1640 medium supplemented with $10 \%$ fetal bovine serum, $100 \mathrm{U} / \mathrm{ml}$ penicillin and $100 \mathrm{U} / \mathrm{ml}$ streptomycin at $37^{\circ} \mathrm{C}$ in a $5 \% \mathrm{CO} 2$ humidified atmosphere for $72 \mathrm{~h}$. Then the cells transfected with RFP-GFP-LC3 lentivirus were treated with different concentrations T-2 toxin for $12 \mathrm{~h}$, and analyzed by laser confocal microscope (ZEISS LSM, German). 


\subsection{Protein extraction and western blot}

After treatment, the L02 cells were lysed with RIPA buffer containing complete Mini protease inhibitor cocktail (Beyotime, Nantong, China). After centrifugation, the supernatant was collected and stored at $-80^{\circ} \mathrm{C}$. Protein $(20 \mu \mathrm{g})$ was loaded for 1-dimensional SDS-PAGE in a discontinuous system using 5-12\% separating gel and 5\% stacking gel. The separated proteins were electrophoretically transferred to polyvinylidene fluoride (PVDF) membranes in a cooled Bio-Rad TransBlot unit. the membranes were then immunoblotted with primary antibodies (anti-Bcl-2 antibody, anti-Bax antibody, anti-PARP-1 antibody, anti-Caspase-3 antibody, antiP62/SQSTM1 antibody, anti-Beclin-1 antibody, anti-LC3 antibody, anti- $\beta$-actin antibody. After washing, membranes were exposed to secondary antibodies. Immunoblots were developed using enhanced chemiluminescence. The photographs generated were quantitatively analyzed with a Quantity One image densitometer. The molecular weights of the protein bands were determined by reference to the standard molecular weight markers. Protein levels were standardized by comparison with anti- $\beta$-actin antibody.

\subsection{Statistical analysis}

The data were expressed as mean $\pm \mathrm{SD}$, and analyzed using One-way ANOVA, followed by LSD's post hoc test using SPSS 20.0 statistical software. The level of significance was accepted at $\mathrm{P}<0.05$. 


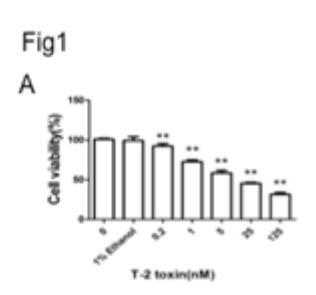

B
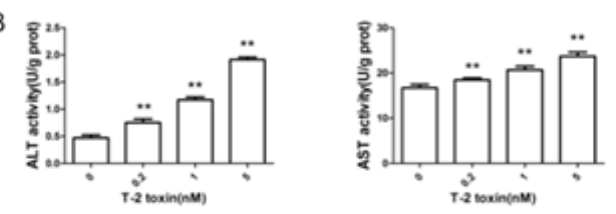

C

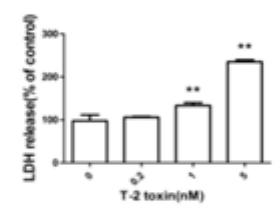

D
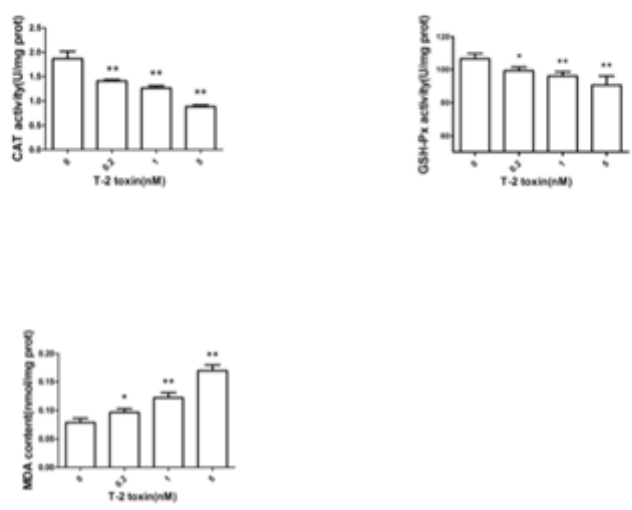

Fig 1. T-2 toxin-induced cytotoxicity effect and oxidative stress in L02 cells. Cells were treated with absence or presence of T-2 toxin at different concentrations for $12 \mathrm{~h}$. (A) The cultured L02 cells were treated with increasing concentration of T- 2 toxin dissolved in ethanol (0-125 nM, $12 \mathrm{~h})$ and MTT assay was used to assess the cytotoxic effects on the viability. (B) The levels of ALT, AST and LDH (C) present in the cell culture medium were determined enzymatically using commercial kits (Naning KeyGen Biotech). Results are expressed as mean $\pm \mathrm{SD}, \mathrm{n}=6$ for each group. $* * \mathrm{P}<0.01,{ }^{*} \mathrm{P}<0.05$ and considered significantly different from control values. (D) GSH-Px and CAT activity of the cultured L02 cells treated with T-2 toxin were determined enzymatically 
using commercial kits. Values are the means \pm SD of three independent experiments. ${ }^{*} * \mathrm{P}<0.01, * \mathrm{P}<0.05$ and considered significantly different from control values. 


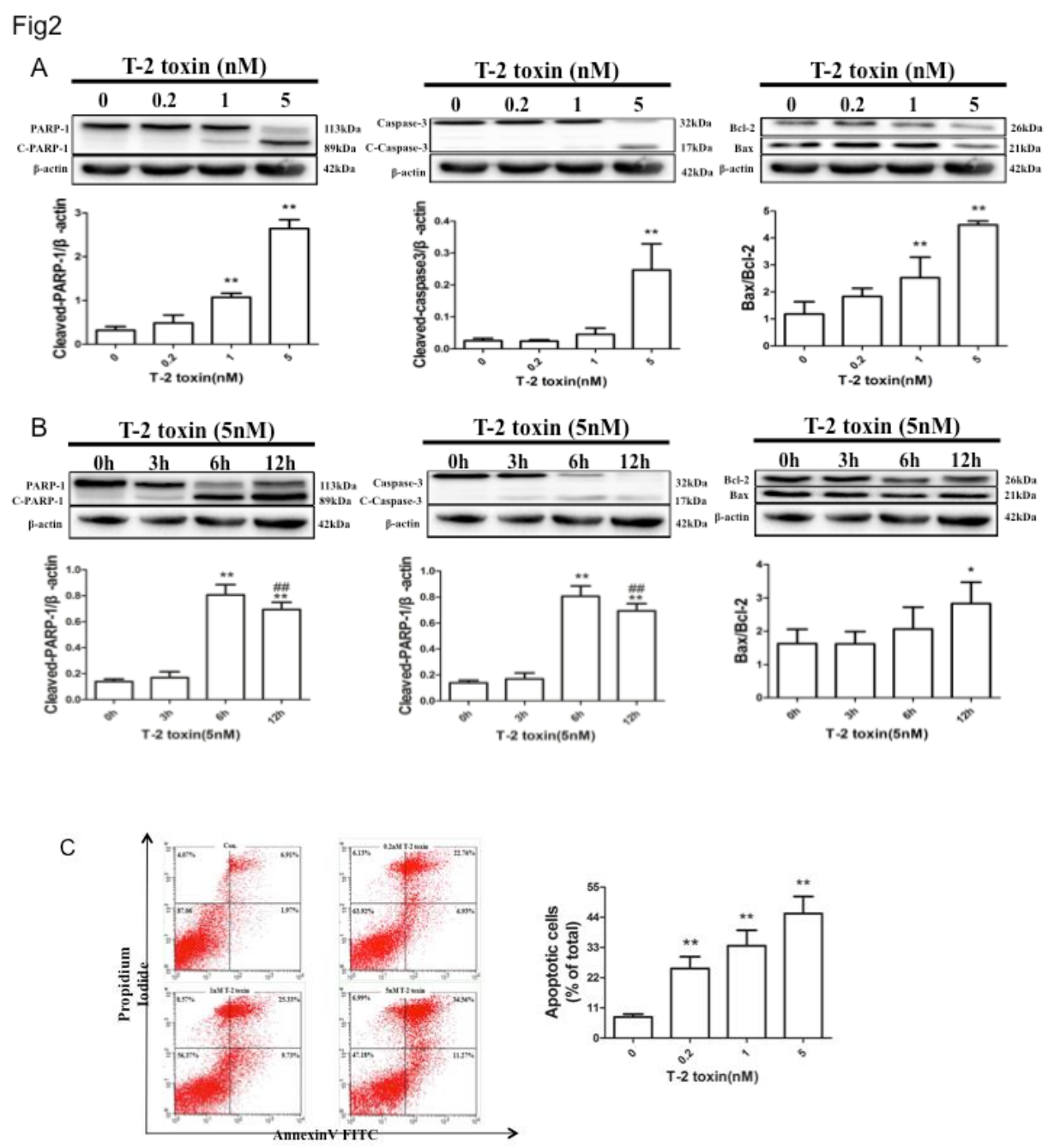

D

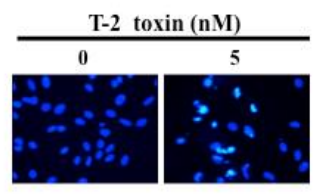

Fig 2. T-2 toxin induced apoptosis in L02 cells. (A) Dose-dependent effects on the T-2 toxin-induced apoptosis. Cells were treated with T-2 toxin $(0,0.21$ and $5 \mathrm{nM}, 12 \mathrm{~h})$ and the T-2 toxin-induced effects on PARP-1, caspase-3 and Bax/Bcl-2 proteins in L02 cells were determined by western blotting. Results are expressed as mean $\pm \mathrm{SD}, \mathrm{n}=3$ for each group. ${ }^{*} \mathrm{p}<0.01,{ }^{*} \mathrm{p}<0.05$ and considered significantly different from control values. (B) Time course of the T-2 toxin-induced effects $(0,3,6$, and $12 \mathrm{~h}, 5 \mathrm{nM})$ on PARP-1, caspase-3, and Bax/Bcl-2 proteins were determined by western blotting. 
Values are the means $\pm \mathrm{SD}$ of three independent experiments. $* * \mathrm{P}<0.01, * \mathrm{P}<0.05$ and

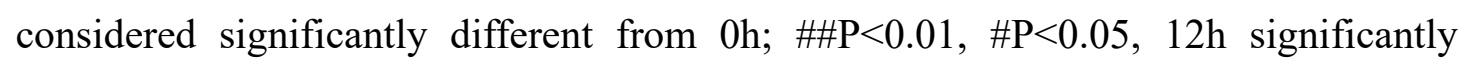
different from 6h. (C) Flow cytometry analysis of T-2 toxin-induced apoptosis in L02 cells. L02 cells treated with T-2 toxin $(0,0.2,1$, and $5 \mathrm{nM}, 12 \mathrm{~h})$ and stained with propidium iodine and FITC-labeled Annexin V. Quantification of of the apoptotic cells are shown in the histogram on the right. Data are presented as mean $\pm \mathrm{SD}, \mathrm{n}=3$ for each group. $* * \mathrm{P}<0.01, * \mathrm{P}<0.05$ and considered highly significant difference from the control. (D) Nuclear fragmentation of the cultured L02 cells induced by T-2 toxin ( $5 \mathrm{nM}, 24 \mathrm{~h}$ ) was analyzed by fluorescent microscopy (cells were stained with Hoechst 33258 dye). 
Fig3
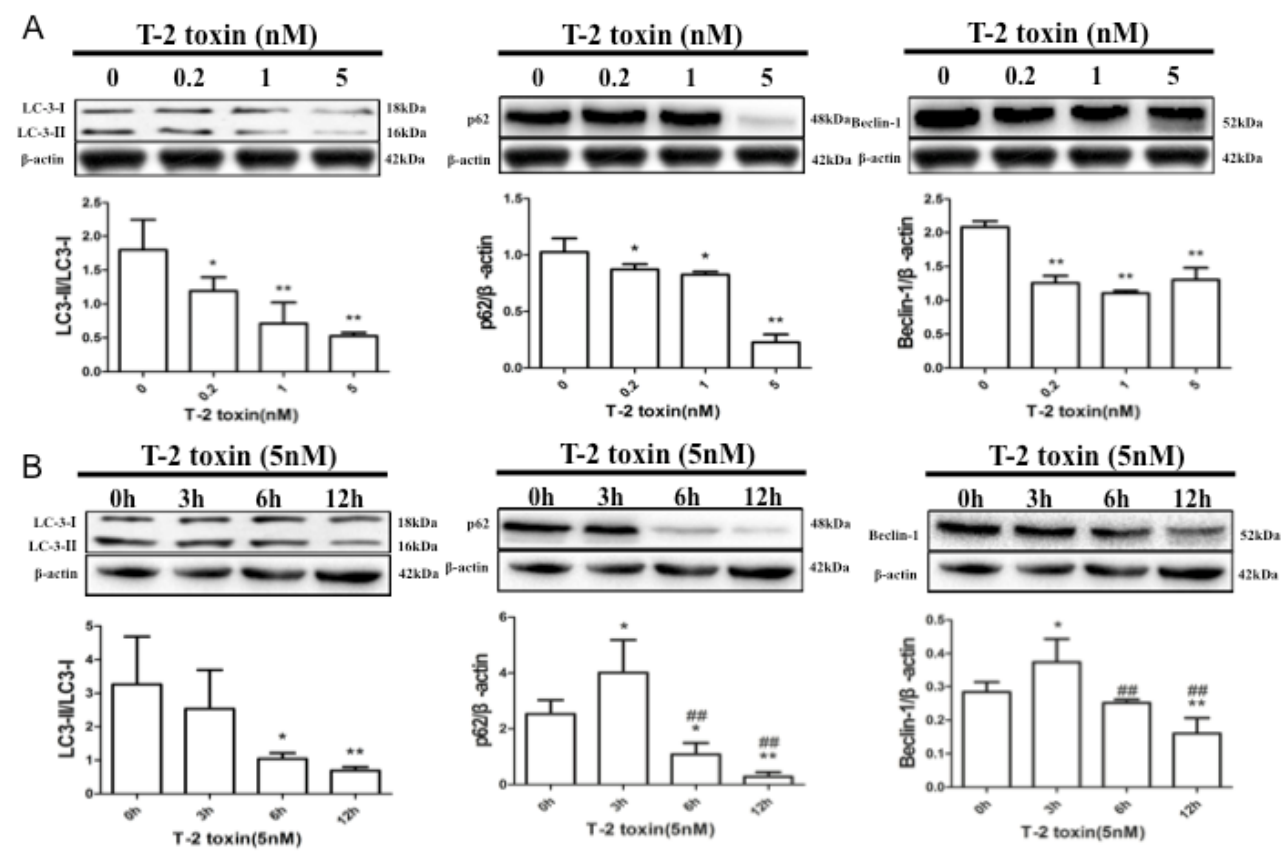

C

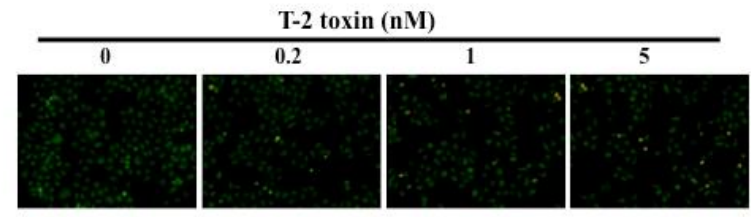

D

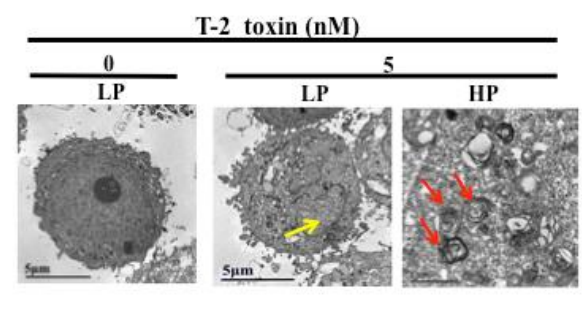

$\mathrm{E}$

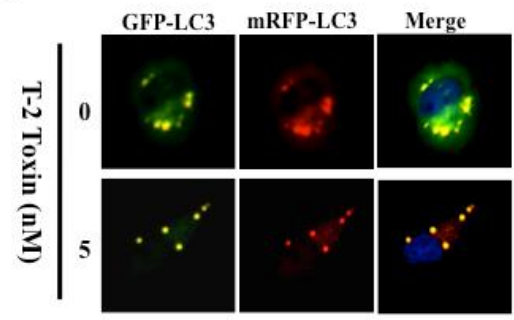

Fig 3. T-2 toxin induced autophagy in L02 cells. (A) Dose-dependent alteration of the autophagy proteins. Cells were treated with T-2 toxin $(0,0.2,1$ and $5 \mathrm{nM}, 12 \mathrm{~h})$ and LC3-II/LC3-I, p62 and Beclin-1 proteins were analyzed by the western blotting. Results are expressed as mean $\pm \mathrm{SD}, \mathrm{n}=3$ for each group. ${ }^{*} * \mathrm{P}<0.01, * \mathrm{P}<0.05$ and considered significantly different from control values. (B) Time course analysis of the T-2 toxin-treated L02 cells. The cells were exposed to T-2 toxin $(0,3,6$, and $12 \mathrm{~h}$, 5nM) and LC3-II/LC3-I, P62 and beclin-1 proteins levels were determined by western 
blotting. Values are the means $\pm \mathrm{SD}$ of three independent experiments. $* * \mathrm{P}<0.01$, $* \mathrm{P}<0.05$ and considered significantly different from $0 \mathrm{~h} ; \# \# \mathrm{P}<0.01, \# \mathrm{P}<0.05,12 \mathrm{~h}$ and 6h significantly different from $3 \mathrm{~h}$. (C) L02 cells were treated with T-2 toxin $(0,0.2$, 1, and $5 \mathrm{nM}, 12 \mathrm{~h}$ ) and stained with acridine orange (AO) and AVOs were observed by florescence microscopy (D) Cells were treated T-2 toxin (0 and $5 \mathrm{nM}, 12 \mathrm{~h}$ ), and transmission electron microscopy (TEM) was used to detect the appearance of autolysosomes in L02 cells. Yellow arrow indicates nuclear pyknosis and red arrow indicates autolysosomes (LP, low power and HP, high power). (E) The effect of T-2 toxin on accumulation of autophagosomes. L02 cells were transfected with RFP-GFPLC3 lentivirus for $72 \mathrm{~h}$, and with and without T-2 toxin (12h). The lentivirus allows distinction of autophagosomes (GFP+, RFP+, yellow puncta) and autolysosomes (GFP$-\mathrm{RFP}+$ red puncta) as GFP fluorescence is quenched in the acidic autolysosomes. 


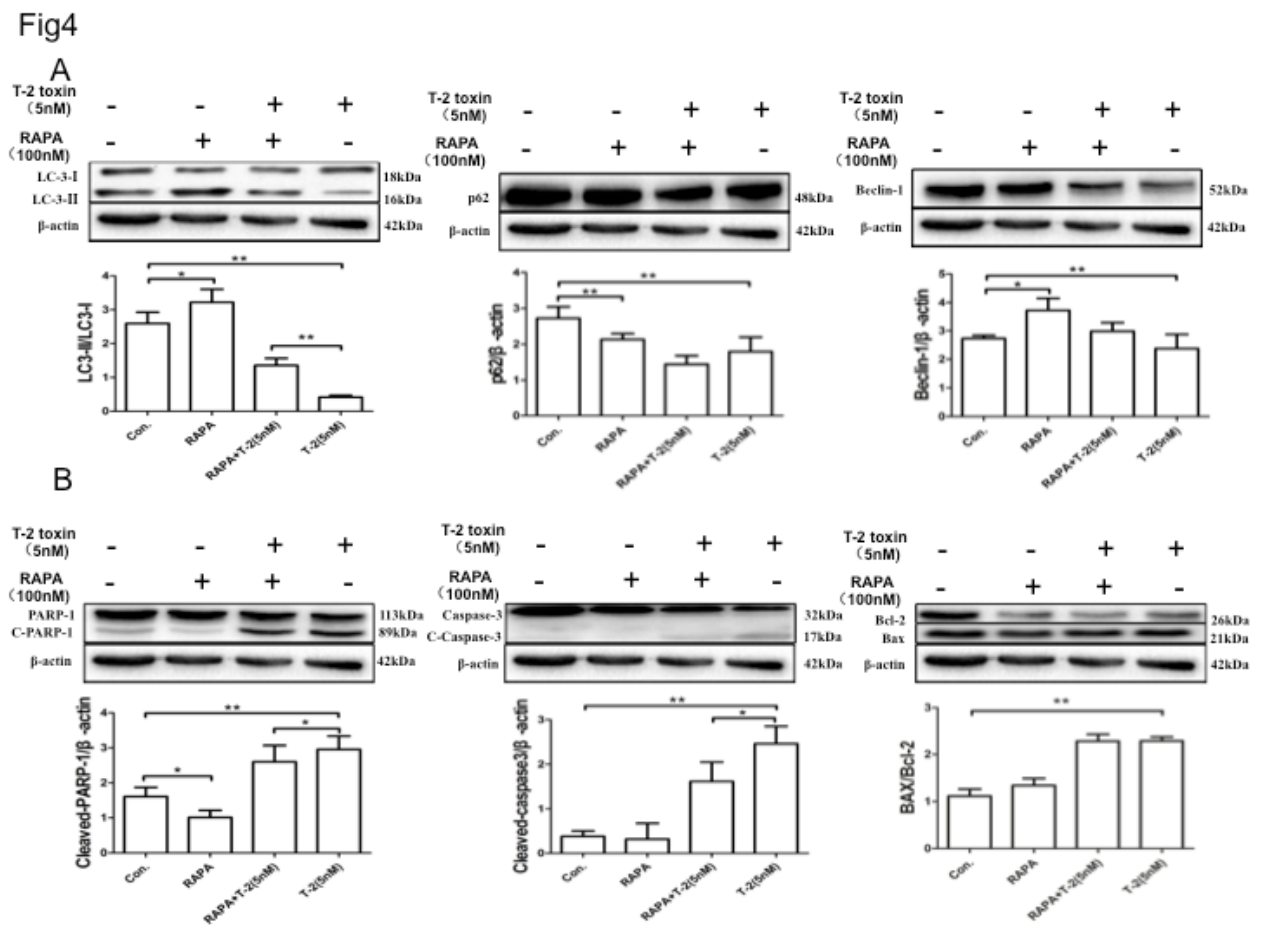

C

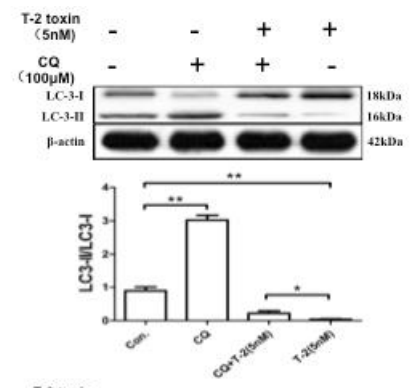

D $\underset{(5 n M)}{T-2 \text { toxin }}-\quad-++$

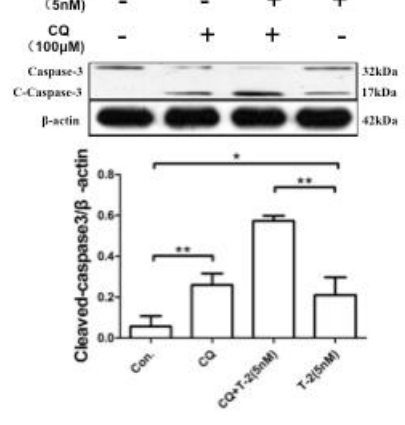

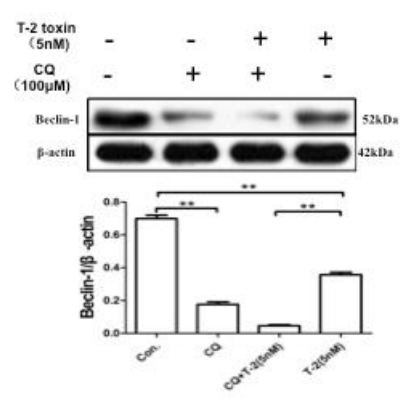




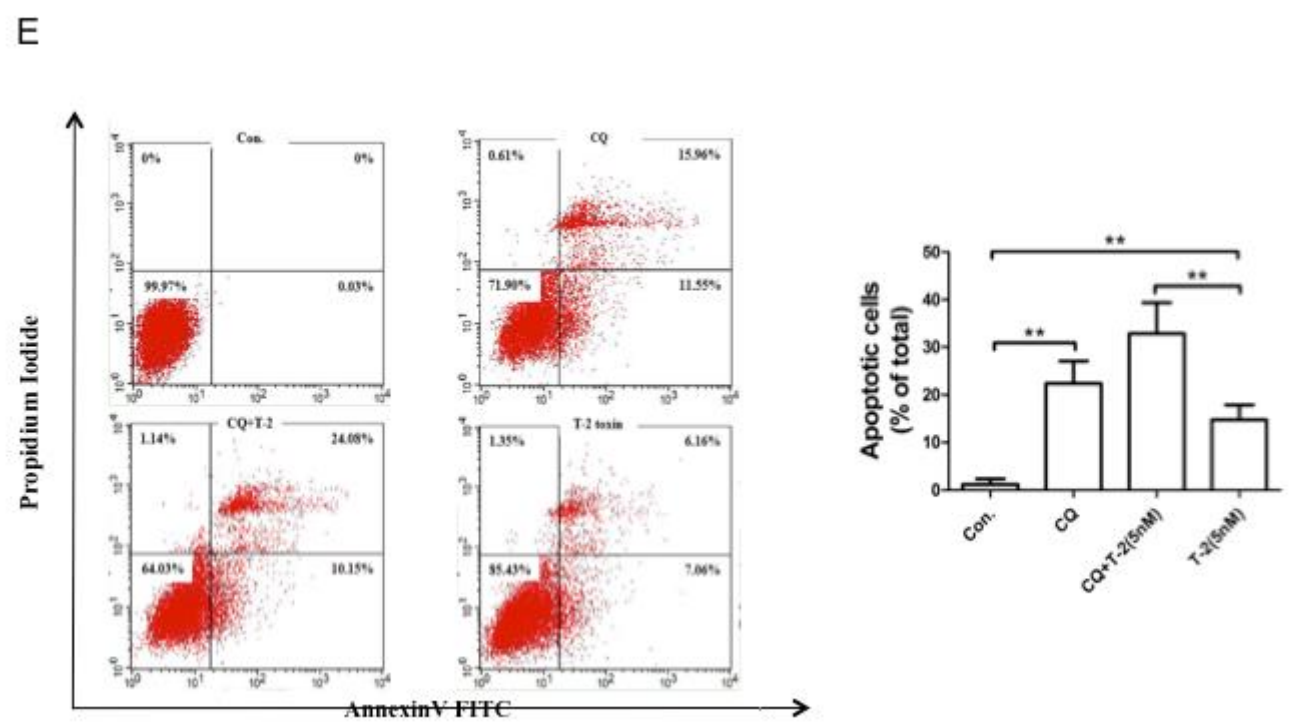

Fig 4. Interactions of autophagy and apoptosis induced by T-2 toxin in L02 cells. (A) Effect of RAPA on T-2 toxin-induced autophagy. L02 cells were pretreated with autophagy stimulator RAPA $(100 \mathrm{nM})$ for $24 \mathrm{~h}$, and cells were co-treated with T-2 toxin $(5 \mathrm{nM})$ for additional 12h. The levels of LC3-II/LC3-I, p62 and beclin-1 proteins were analyzed by western blotting. (B) Effect of RAPA on T-2 toxin-induced apoptosis. L02 cells were pretreated with autophagy stimulator RAPA (100 nM) for 24h, and exposure to the stimulator was continued during subsequent T-2 toxin $(5 \mathrm{nM})$ treatment for $12 \mathrm{~h}$. The levels of the apoptotic related proteins, PARP-1, caspase-3 and Bax/Bcl-2 were analyzed by the western blotting. (C) Effect of autophagy inhibitor CQ on autophagy and apoptosis associated proteins in T-2 toxin treated cells. L02 cells were pretreated with autophagy inhibitor CQ $(100 \mu \mathrm{M})$ for 1h, and exposure to the inhibitor was continued during subsequent T-2 toxin (5 nM) treatment for $6 \mathrm{~h}$. LC3-II/LC3-I, beclin-1 and caspase 3 proteins were analyzed by western blotting. (D) Effect of CQ on T-2 toxin-induced apoptosis. L02 cells were pretreated with autophagy inhibitor CQ $(100 \mu \mathrm{M})$ for $1 \mathrm{~h}$, and exposure to the inhibitor was continued during subsequent T-2 toxin $(5 \mathrm{nM})$ treatment for $6 \mathrm{~h}$. Western blotting was used for analysis of caspase-3 proteins. (E) The T-2 toxin induced apoptosis was greatly enhanced upon inhibition of the autophagy. The L02 cells were treated as described in D and cells were analyzed 
for apoptosis by flow cytometry. Data are presented as mean $\pm \mathrm{SD}, \mathrm{n}=3$ for each group. ${ }^{*} * \mathrm{P}<0.01(2010),{ }^{*} \mathrm{P}<0.05$. 


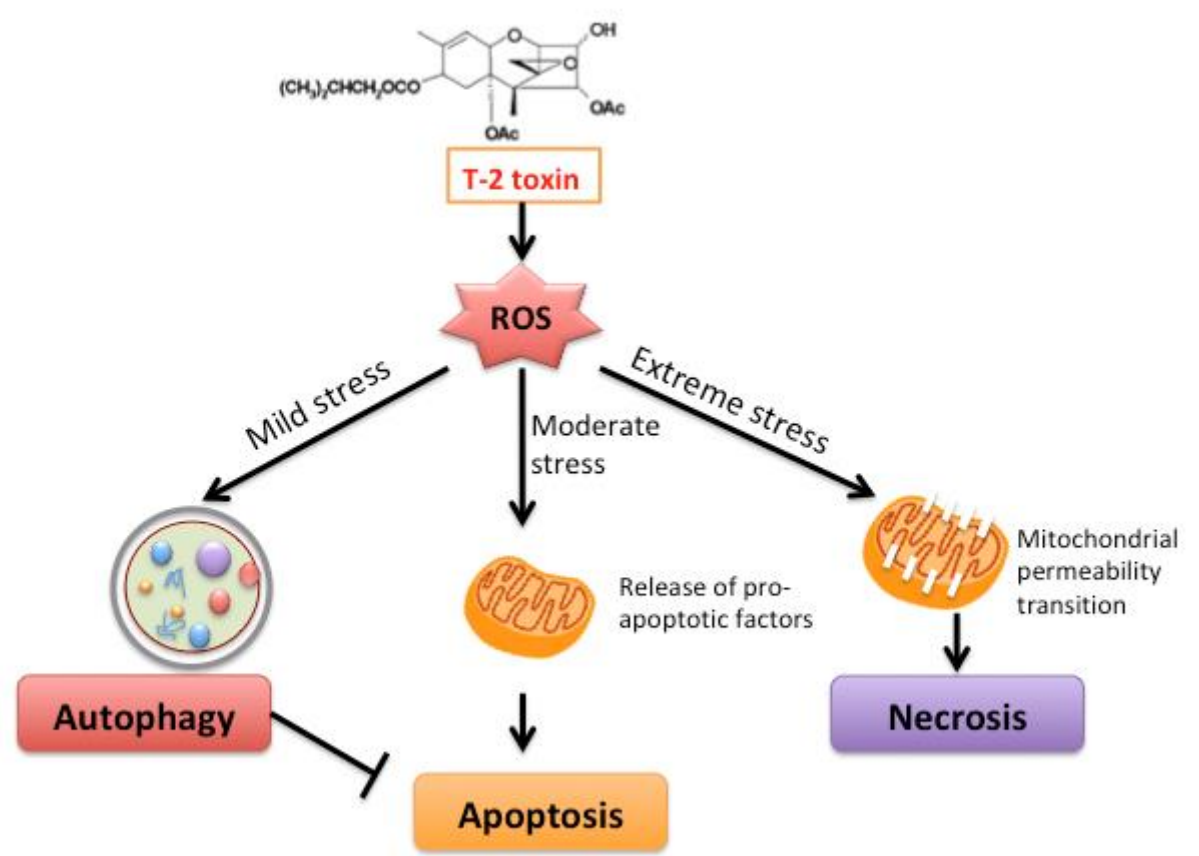

Fig 5. Schematic illustration of the T-2 toxin-induced autophagy and apoptosis. Under the mild stress, the liver cells activate the mechanism of autophagy to protect the cells from the stress-induced damage at same time suppress the apoptosis. When the stress levels increase the apoptosis pathway will be activated. Under severe stress conditions, the outright necrosis will begin leading to destruction of tissues. 


\section{References}

1. Creppy, E.E. Update of survey, regulation and toxic effects of mycotoxins in Europe. Toxicology letters 2002, 127, 19-28.

2. De Ruyck, K.; De Boevre, M.; Huybrechts, I.; De Saeger, S. Dietary mycotoxins, co-exposure, and carcinogenesis in humans: Short review. Mutation Research/Reviews in Mutation Research 2015, 766, 32-41.

3. Organization, W.H. Selected mycotoxins: ochratoxins, trichothecenes, ergot. 1990.

4. Yao, Y.-f.; Li, X.-b.; Yang, J.; Shen, B.; Zhou, Z.-k.; Pei, F.-x. Study on the effect of T-2 toxin combined with low nutrition diet on rat epiphyseal plate growth and development. International orthopaedics 2010, 34, 1351-1356.

5. Chen, J.; Chu, Y.; Cao, J.; Yang, Z.; Guo, X.; Wang, Z. T-2 toxin induces apoptosis, and selenium partly blocks, T-2 toxin induced apoptosis in chondrocytes through modulation of the Bax/Bcl-2 ratio. Food and chemical toxicology 2006, 44, 567-573.

6. Nagase, M.; Alam, M.M.; Tsushima, A.; YOSHIZAWA, T.; SAKATO, N. Apoptosis induction by T-2 toxin: activation of caspase-9, caspase-3, and DFF40/CAD through cytosolic release of cytochrome c in HL-60 cells. Bioscience, biotechnology, and biochemistry 2001, 65, 1741-1747.

7. Zhuang, Z.; Yang, D.; Huang, Y.; Wang, S. Study on the apoptosis mechanism induced by T-2 toxin. PloS one 2013, 8, e83105.

8. Wang, X.; Liu, Q.; Ihsan, A.; Huang, L.; Dai, M.; Hao, H.; Cheng, G.; Liu, Z.; Wang, Y.; Yuan, Z. JAK/STAT pathway plays a critical role in the proinflammatory gene expression and apoptosis of RAW264. 7 cells induced by trichothecenes as DON and T-2 toxin. Toxicological Sciences 2012, 127, 412424.

9. Sehata, S.; Kiyosawa, N.; Makino, T.; Atsumi, F.; Ito, K.; Yamoto, T.; Teranishi, M.; Baba, Y.; Uetsuka, K.; Nakayama, H. Morphological and microarray analysis of T-2 toxin-induced rat fetal brain lesion. Food and chemical toxicology 2004, 42, 1727-1736. 
10. Doi, K.; Ishigami, N.; Sehata, S. T-2 toxin-induced toxicity in pregnant mice and rats. International journal of molecular sciences 2008, 9, 2146-2158.

11. Chen, J.-h.; Cao, J.-1.; Chu, Y.-1.; Wang, Z.-1.; Yang, Z.-t.; Wang, H.-1. T-2 toxininduced apoptosis involving Fas, p53, Bcl-xL, Bcl-2, Bax and caspase-3 signaling pathways in human chondrocytes. Journal of Zhejiang University SCIENCE B 2008, 9, 455-463.

12. Han, J.; Guo, X.; Wu, C.; Li, C.; He, S.; Duan, C.; Ning, Y. Nano-Se-chondroitin sulfate inhibits T-2 toxin-induced apoptosis of cultured chondrocytes from patients with Kashin-Beck disease. Nan fang yi ke da xue xue bao= Journal of Southern Medical University 2013, 33, 225-229.

13. Weidner, M.; Lenczyk, M.; Schwerdt, G.; Gekle, M.; Humpf, H.-U. Neurotoxic potential and cellular uptake of T-2 toxin in human astrocytes in primary culture. Chemical research in toxicology 2013, 26, 347-355.

14. Fang, H.; Wu, Y.; Guo, J.; Rong, J.; Ma, L.; Zhao, Z.; Zuo, D.; Peng, S. T-2 toxin induces apoptosis in differentiated murine embryonic stem cells through reactive oxygen species-mediated mitochondrial pathway. Apoptosis 2012, 17, 895-907.

15. Wang, J.; Jiang, J.; Zhang, H.; Wang, J.; Cai, H.; Li, C.; Li, K.; Liu, J.; Guo, X.; Zou, G. Integrated transcriptional and proteomic analysis with in vitro biochemical assay reveal the important role of CYP3A46 in T-2 toxin hydroxylation in porcine primary hepatocytes. Molecular \& Cellular Proteomics 2011, mcp. M111. 008748.

16. Shinozuka, J.; Suzuki, M.; Noguchi, N.; Sugimoto, T.; Uetsuka, K.; Nakayama, H.; Doi, K. T-2 toxin-induced apoptosis in hematopoietic tissues of mice. Toxicologic pathology 1998, 26, 674-681.

17. Albarenque, S.M.; Shinozuka, J.; Iwamoto, S.; Nakayama, H.; Doi, K. T-2 toxin-induced acute skin lesions in Wistar-derived hypotrichotic WBNIILA-Ht rats. Histology and histopathology 1999, 14, 337-342.

18. Wu, J.; Tu, D.; Yuan, L.-Y.; Yi, J.-e.; Tian, Y. T-2 toxin regulates steroid hormone secretion of rat ovarian granulosa cells through cAMP-PKA pathway. 
Toxicology letters 2015, 232, 573-579.

19. Kiessling, K.-H. Biochemical mechanism of action of mycotoxins. Pure and applied chemistry 1986, 58, 327-338.

20. Wu, J.; Tu, D.; Yuan, L.-Y.; Yuan, H.; Wen, L.-X. T-2 toxin exposure induces apoptosis in rat ovarian granulosa cells through oxidative stress. Environmental toxicology and pharmacology 2013, 36, 493-500.

21. Yuan, Z.; Matias, F.B.; Yi, J.-e.; Wu, J. T-2 toxin-induced cytotoxicity and damage on TM3 Leydig cells. Comparative Biochemistry and Physiology Part C: Toxicology \& Pharmacology 2016, 181, 47-54.

22. Wu, J.; Huang, W.; Xiao, H.; Xie, Y.; Yuan, Z.; Yi, J.; Chen, J.; Tu, D.; Tian, Y. Procyanidins B2 reverses the T-2 toxin-induced mitochondrial apoptosis in TM3 Leydig cells. Journal of Functional Foods 2018, 45, 118-128.

23. Carew, J.S.; Kelly, K.R.; Nawrocki, S.T. Autophagy as a target for cancer therapy: new developments. Cancer management and research 2012, 4, 357.

24. Glick, D.; Barth, S.; Macleod, K.F. Autophagy: cellular and molecular mechanisms. The Journal of pathology 2010, 221, 3-12.

25. Kim, K.-Y.; Park, K.-I.; Kim, S.-H.; Yu, S.-N.; Park, S.-G.; Kim, Y.; Seo, Y.-K.; Ma, J.-Y.; Ahn, S.-C. Inhibition of autophagy promotes salinomycin-induced apoptosis via reactive oxygen species-mediated PI3K/AKT/mTOR and ERK/p38 MAPK-dependent signaling in human prostate cancer cells. International journal of molecular sciences 2017, 18, 1088.

26. Luo, S.; Rubinsztein, D. Apoptosis blocks Beclin 1-dependent autophagosome synthesis: an effect rescued by Bcl-xL. Cell death and differentiation 2010, 17, 268.

27. Pagliarini, V.; Wirawan, E.; Romagnoli, A.; Ciccosanti, F.; Lisi, G.; Lippens, S.; Cecconi, F.; Fimia, G.; Vandenabeele, P.; Corazzari, M. Proteolysis of Ambra1 during apoptosis has a role in the inhibition of the autophagic pro-survival response. Cell death and differentiation 2012, 19, 1495.

28. Wirawan, E.; Walle, L.V.; Kersse, K.; Cornelis, S.; Claerhout, S.; Vanoverberghe, I.; Roelandt, R.; De Rycke, R.; Verspurten, J.; Declercq, W. 
Caspase-mediated cleavage of Beclin-1 inactivates Beclin-1-induced autophagy and enhances apoptosis by promoting the release of proapoptotic factors from mitochondria. Cell death \& disease 2011, 1 , e18.

29. Mariño, G.; Niso-Santano, M.; Baehrecke, E.H.; Kroemer, G. Self-consumption: the interplay of autophagy and apoptosis. Nature reviews Molecular cell biology 2014, 15,81 .

30. Wu, J.; Jing, L.; Yuan, H.; Peng, S.-q. T-2 toxin induces apoptosis in ovarian granulosa cells of rats through reactive oxygen species-mediated mitochondrial pathway. Toxicology letters 2011, 202, 168-177.

31. Velmurugan, B.; Selvanayagam, M.; Cengiz, E.I.; Unlu, E. Histopathology of lambda-cyhalothrin on tissues (gill, kidney, liver and intestine) of Cirrhinus mrigala. Environmental Toxicology and Pharmacology 2007, 24, 286-291.

32. Bouaziz, C.; El Golli, E.; Abid-Essefi, S.; Brenner, C.; Lemaire, C.; Bacha, H. Different apoptotic pathways induced by zearalenone, T-2 toxin and ochratoxin A in human hepatoma cells. Toxicology 2008, 254, 19-28.

33. Caloni, F.; Ranzenigo, G.; Cremonesi, F.; Spicer, L.J. Effects of a trichothecene, T-2 toxin, on proliferation and steroid production by porcine granulosa cells. Toxicon 2009, 54, 337-344.

34. El Golli, E.; Hassen, W.; Bouslimi, A.; Bouaziz, C.; Ladjimi, M.M.; Bacha, H. Induction of Hsp 70 in Vero cells in response to mycotoxins: Cytoprotection by sub-lethal heat shock and by Vitamin E. Toxicology letters 2006, 166, 122-130.

35. Wu, Q.-H.; Wang, X.; Yang, W.; Nüssler, A.K.; Xiong, L.-Y.; Kuča, K.; Dohnal, V.; Zhang, X.-J.; Yuan, Z.-H. Oxidative stress-mediated cytotoxicity and metabolism of T-2 toxin and deoxynivalenol in animals and humans: an update. Archives of toxicology 2014, 88, 1309-1326.

36. Landmesser, U.; Harrison, D.G. Oxidative stress and vascular damage in hypertension. Coronary artery disease 2001, 12, 455-461.

37. Ozguner, F.; Koyu, A.; Cesur, G. Active smoking causes oxidative stress and decreases blood melatonin levels. Toxicology and Industrial Health 2005, 21, 21-26. 
38. Cipriani, G.; Rapizzi, E.; Vannacci, A.; Rizzuto, R.; Moroni, F.; Chiarugi, A. Nuclear poly (ADP-ribose) polymerase-1 rapidly triggers mitochondrial dysfunction. Journal of Biological Chemistry 2005, 280, 17227-17234.

39. Anilkumar, U.; Prehn, J.H. Anti-apoptotic BCL-2 family proteins in acute neural injury. Frontiers in cellular neuroscience 2014, 8, 281.

40. Oltval, Z.N.; Milliman, C.L.; Korsmeyer, S.J. Bcl-2 heterodimerizes in vivo with a conserved homolog, Bax, that accelerates programed cell death. cell 1993, 74, 609-619.

41. Primikyri, A.; Chatziathanasiadou, M.V.; Karali, E.; Kostaras, E.; Mantzaris, M.D.; Hatzimichael, E.; Shin, J.-S.; Chi, S.-W.; Briasoulis, E.; Kolettas, E. Direct binding of Bcl-2 family proteins by quercetin triggers its pro-apoptotic activity. ACS chemical biology 2014, 9, 2737-2741.

42. Antonsson, B. Bax and other pro-apoptotic Bcl-2 family" killer-proteins" and their victim the mitochondrion. Cell and tissue research 2001, 306, 347-361.

43. Tang, W.; Liu, J.-W.; Zhao, W.-M.; Wei, D.-Z.; Zhong, J.-J. Ganoderic acid T from Ganoderma lucidum mycelia induces mitochondria mediated apoptosis in lung cancer cells. Life sciences 2006, 80, 205-211.

44. Borner, C. The Bcl-2 protein family: sensors and checkpoints for life-or-death decisions. Molecular immunology 2003, 39, 615-647.

45. Liu, Y.; Xu, H.; An, M. mTORC1 regulates apoptosis and cell proliferation in pterygium via targeting autophagy and FGFR3. Scientific reports 2017, 7, 7339.

46. Stanton, M.J.; Dutta, S.; Zhang, H.; Polavaram, N.S.; Leontovich, A.A.; Hönscheid, P.; Sinicrope, F.A.; Tindall, D.J.; Muders, M.H.; Datta, K. Autophagy control by the VEGF-C/NRP-2 axis in cancer and its implication for treatment resistance. Cancer research 2012.

47. Tanida, I.; Minematsu-Ikeguchi, N.; Ueno, T.; Kominami, E. Lysosomal turnover, but not a cellular level, of endogenous LC3 is a marker for autophagy. Autophagy 2005, 1, 84-91.

48. Yoshii, S.R.; Mizushima, N. Monitoring and measuring autophagy. International journal of molecular sciences 2017, 18, 1865. 
49. Mizushima, N.; Yoshimori, T. How to interpret LC3 immunoblotting. Autophagy 2007, 3, 542-545.

50. Mizushima, N.; Yoshimori, T.; Levine, B. Methods in mammalian autophagy research. Cell 2010, 140, 313-326.

51. Du, D.; Hu, L.; Wu, J.; Wu, Q.; Cheng, W.; Guo, Y.; Guan, R.; Wang, Y.; Chen, X.; Yan, X. Neuroinflammation contributes to autophagy flux blockage in the neurons of rostral ventrolateral medulla in stress-induced hypertension rats. Journal of neuroinflammation 2017, 14, 169.

52. Bjørkøy, G.; Lamark, T.; Brech, A.; Outzen, H.; Perander, M.; Øvervatn, A.; Stenmark, H.; Johansen, T. p62/SQSTM1 forms protein aggregates degraded by autophagy and has a protective effect on huntingtin-induced cell death. The Journal of cell biology 2005, 171, 603-614.

53. Pankiv, S.; Clausen, T.H.; Lamark, T.; Brech, A.; Bruun, J.-A.; Outzen, H.; Øvervatn, A.; Bjørkøy, G.; Johansen, T. p62/SQSTM1 binds directly to Atg8/LC3 to facilitate degradation of ubiquitinated protein aggregates by autophagy. Journal of biological chemistry 2007.

54. Klionsky, D.J.; Abdelmohsen, K.; Abe, A.; Abedin, M.J.; Abeliovich, H.; Acevedo Arozena, A.; Adachi, H.; Adams, C.M.; Adams, P.D.; Adeli, K. Guidelines for the use and interpretation of assays for monitoring autophagy. Autophagy 2016, 12, 1-222.

55. Fu, L.-1.; Cheng, Y.; Liu, B. Beclin-1: autophagic regulator and therapeutic target in cancer. The international journal of biochemistry \& cell biology 2013, $45,921-924$

56. Xie, Z.; Klionsky, D.J. Autophagosome formation: core machinery and adaptations. Nature cell biology 2007, 9, 1102.

57. Liu, G.; Yuan, Y.; Long, M.; Luo, T.; Bian, J.; Liu, X.; Gu, J.; Zou, H.; Song, R.; Wang, Y. Beclin-1-mediated autophagy protects against cadmium-activated apoptosis via the Fas/FasL pathway in primary rat proximal tubular cell culture. Scientific reports 2017, 7, 977.

58. Ciechomska, I.; Goemans, G.; Skepper, J.; Tolkovsky, A. Bcl-2 complexed with 
Beclin-1 maintains full anti-apoptotic function. Oncogene 2009, 28, 2128.

59. Djavaheri-Mergny, M.; Maiuri, M.; Kroemer, G. Cross talk between apoptosis and autophagy by caspase-mediated cleavage of Beclin 1. Oncogene 2010, 29, 1717.

60. Kang, R.; Zeh, H.; Lotze, M.; Tang, D. The Beclin 1 network regulates autophagy and apoptosis. Cell death and differentiation 2011, 18, 571. 